\title{
Estimation Problems in the Block-Diagonal Model of the Multitrait-Multimethod Matrix
}

\author{
Michael T. Brannick and Paul E. Spector \\ University of South Florida
}

The most popular method used to analyze the multitrait-multimethod (MTMM) matrix has been confirmatory factor analysis (CFA). The block-diagonal model, in which trait effects, trait correlations, method effects, and method correlations are simultaneously estimated is examined in detail. Analysis of published data from 18 correlation matrices showed estimation problems in all but one case. Simulations were used to show how identification and specification difficulties may account for these problems. Even trivial misspecification of a single parameter can prevent program convergence. These problems render the CFA block-diagonal approach to analyzing мтMм data less useful than has generally been thought. Index terms: construct validity, covariance structure modeling, factor analysis, multitrait-multimethod matrix, parameter estimation in confirmatory factor analysis.

The multitrait-multimethod (MTMM) matrix, devised by Campbell and Fiske (1959), remains one of the most elegant and useful means of evaluating the validity of psychological measures. A variety of quantitative and statistical approaches to evaluating the MTMM matrix have been proposed, including analysis of variance, partial correlations, exploratory factor analysis, path analysis, covariance component analysis, direct product models, and confirmatory factor analysis (CFA; Schmitt \& Stults, 1986). CFA currently appears to be the most popular approach, and the analysis favored for most purposes by Schmitt and Stults (1986).

In the most general CFA model typically fit to data, trait loadings, method loadings, inter-trait correlations, and inter-method correlations are all estimated. An illustration of such a model is

APPLIED PSYCHOLOGICAL MEASUREMENT

Vol. 14, No. 4, December 1990, pp. 325-339

(C) Copyright 1990 Appled Psychological Measurement Inc. 0146-62/6/90/040325-15\$2.00 shown in Table 1 (the letters A through $\mathrm{X}$ represent factor loadings or correlations that are discussed below). Models of this type were referred to as block-diagonal by Wothke (1984, 1987), and as Model 3C by Widaman (1985). In the block-diagonal model, a single factor is hypothesized for each trait and for each method. Each observed variable has loadings estimated (freed) for one of the trait factors and one of the method factors, so that the variance for a single observed variable is decomposed into variance due to a single trait, a single method, and uniqueness. The uniqueness estimate contains both random measurement error and systematic variance uncorrelated with the hypothesized factors.

Marsh and Hocevar (1988) presented models

Table 1

Block-Diagonal Model With

Three Traits $\left(T_{1}, T_{2}, T_{3}\right)$

and Three Methods $\left(M_{1}, M_{2}, M_{3}\right)$

\begin{tabular}{|c|c|c|c|c|c|c|}
\hline \multirow{2}{*}{$\begin{array}{l}\text { Observed } \\
\text { Variable }\end{array}$} & \multicolumn{3}{|c|}{ Trait Factor } & \multicolumn{3}{|c|}{ Method Factor } \\
\hline & $T_{1}$ & $\mathrm{~T}_{2}$ & $\mathrm{~T}_{3}$ & $\mathbf{M}_{1}$ & $\mathbf{M}_{2}$ & $\mathbf{M}_{3}$ \\
\hline \multicolumn{7}{|c|}{$\mathbf{\Lambda}$ (Factor Loadings) } \\
\hline $\mathrm{X}_{1}$ & A & 0.0 & 0.0 & $\mathbf{J}$ & 0.0 & \\
\hline $\mathrm{X}_{2}$ & 0.0 & D & 0.0 & $\mathrm{~K}$ & 0.0 & 0.0 \\
\hline$x_{3}$ & 0.0 & 0.0 & $\mathrm{G}$ & $\mathbf{L}$ & 0.0 & 0.0 \\
\hline $\mathrm{X}_{4}$ & B & 0.0 & 0.0 & 0.0 & $\mathbf{M}$ & 0.0 \\
\hline $\mathrm{X}_{s}$ & 0.0 & $\mathrm{E}$ & 0.0 & 0.0 & $\mathbf{N}$ & 0.0 \\
\hline$x_{6}$ & 0.0 & 0.0 & $\mathrm{H}$ & 0.0 & $\mathrm{O}$ & 0.0 \\
\hline $\mathrm{X}_{7}$ & $\mathrm{C}$ & 0.0 & 0.0 & 0.0 & 0.0 & $\mathbf{P}$ \\
\hline $\mathrm{X}_{\mathrm{g}}$ & 0.0 & $\mathrm{~F}$ & 0.0 & 0.0 & 0.0 & \\
\hline $\mathrm{X}_{9}$ & 0.0 & 0.0 & I & 0.0 & 0.0 & $\mathbf{R}$ \\
\hline \multicolumn{7}{|c|}{$\Phi$ (Factor Correlations) } \\
\hline$T_{1}$ & 1.0 & & & & & \\
\hline$T_{2}$ & $\mathbf{S}$ & 1.0 & & & & \\
\hline $\mathrm{T}_{3}$ & $T$ & $\mathrm{U}$ & 1.0 & & & \\
\hline $\mathbf{M}_{1}$ & 0.0 & 0.0 & 0.0 & 1.0 & & \\
\hline $\mathbf{M}_{2}$ & 0.0 & 0.0 & 0.0 & $\mathrm{~V}$ & 1.0 & \\
\hline $\mathbf{M}_{3}$ & 0.0 & 0.0 & 0.0 & W & $\mathrm{X}$ & 1.0 \\
\hline
\end{tabular}


that separately estimate specific variance and error. Factor correlations are estimated for trait factors and for method factors, but the trait-method correlations are assumed to be 0 . The blockdiagonal model is of interest because it is the model typically hypothesized to account for MTMM data (e.g., Farh, Hoffman, \& Hegarty, 1984; Marsh \& Hocevar, 1988; Widaman, 1985), and because it plays a central role in tests of hypotheses devised by Widaman (1985).

The factor model underlying the MTMM matrix shown in Table 1 is

$\boldsymbol{\Sigma}=\boldsymbol{\Lambda} \boldsymbol{\Phi} \boldsymbol{\Lambda}^{\prime}+\boldsymbol{\Theta}$,

where $\boldsymbol{\Sigma}$ is a population correlation matrix, $\boldsymbol{\Lambda}$ is a matrix of factor loadings, $\boldsymbol{\Phi}$ is a matrix of factor correlations, and $\Theta$ is a diagonal matrix that contains uniqueness variances. In practice, an observed MTMM correlation matrix is substituted for $\mathbf{\Sigma}$, and the other matrices are estimated, typically by such computer programs as LISREL (Jöreskog \& Sörbom, 1984) or EQS (Bentler, 1985).

Widaman (1985) described a taxonomy of CFA models, involving hierarchical tests of the blockdiagonal model with simpler models (e.g., correlated traits only, or orthogonal methods only). His approach has gained wide acceptance as the most appropriate for MTMM analysis (e.g., Schmitt \& Stults, 1986; Williams, Cote, \& Buckley, 1989). However, Marsh and Hocevar (1988) noted problems with these models when there is only one variable represented in each method by trait combination, which is characteristic of MTMM matrices. They suggested analyzing the individual items (where possible) from each scale in the MTMM matrix by using higher-order CFA.

Others have also noted problems with CFA for MTMM analysis, including capitalization on chance, subjectivity of interpretation, inability to detect trait by method interaction, and difficulty in accurately specifying models (Campbell \& O'Connell, 1967; Golding \& Seidman, 1974; Jackson, 1971; Schmitt \& Stults, 1986). Frequently encountered problems of computational difficulties and improper solutions (impos- sible values) have been attributed to sampling error and largely have been ignored (e.g., Farh et al., 1984; Widaman, 1985; Williams et al., 1989), although Marsh (1989) has begun to address these problems.

\section{Purpose}

This study had two general aims: to review applications of the block-diagonal model to published MTMM matrices in order to document the widespread estimation problems, and to show possible causes of estimation difficulties in empirical applications of the block-diagonal model by using simulations to motivate discussions of both identification problems and specification error.

\section{Estimation Problems}

\section{Identification Problems}

Data are fit to hypothesized models in CFA to estimate parameters of interest and to evaluate goodness-of-fit. The parameters of a model must be shown to be identified before the parameters are estimated (James, Mulaik, \& Brett, 1982; Long, 1983). The textbook solution to this problem is to show mathematically that each parameter can be estimated from the data, and that each parameter estimate is uniquely determined by the data. If the system of equations implied by the model fails to result in a unique estimate for a parameter, the parameter is underidentified.

The consequence of underidentified parameters is that the same data can yield different parameter estimates with identical goodness-offit measures, and then the data are not useful for distinguishing among the estimates. Thus it is pointless in practice to estimate parameters that are underidentified, and the interpretation of results of such an analysis should be avoided, even if there are no evident computational problems.

Theoretical underidentification, as discussed above, occurs when no unique mathematical solution exists for a parameter. Such a result is ob- 
tained, for example, when the number of parameters to be estimated exceeds the available degrees of freedom. Empirical underidentification is a special identification problem. The parameters of a model may be theoretically identified so that there is a general solution that results in a unique estimate for each parameter. If one parameter takes on a specific unwanted value, however, other parameters may become underidentified. For example, a factor defined by three loadings usually will allow unique estimates of each of the loadings. If one of the loadings takes the value 0 , however, the other loadings will be underidentified. Empirical underidentification is discussed more fully by Dillon, Kumar, and Mulani (1987).

One necessary condition for model identification is that there must be more equations than there are parameters to be estimated. In the block-diagonal MTMM model, this condition is satisfied if there are two methods and four or more traits, two traits and four or more methods, or three or more methods and three or more traits (Schmitt \& Stults, 1986; Wothke, 1984). Even though a model satisfies this necessary condition for identification, it is not sufficient to prove identification.

There does not appear to be any published proof that the block-diagonal model is identified. The set of simultaneous equations for the blockdiagonal model is so complex that mathematical proof concerning whether the model is or is not identified has yet to be shown.

Jöreskog and Sörbom (1984) suggested that if identification of the model is in doubt, two lines of evidence other than mathematical proof might be employed. The first was to use LISREL to estimate the parameters of the model from sample data. If the program does not warn that one of the parameters may not be identified, then the model is most likely identified. The second was to take reasonable parameter estimates and use them in Equation 1, for example, to construct a population correlation matrix. This matrix is input to LISREL, and the parameters are estimated. If the program recovers the parameters used to construct the population matrix, then the model is most likely identified.

\section{Specification Errors}

A model is misspecified when the model assumed to account for the data is incorrect. In CFA analyses, the researcher must assume the number of factors, known values for factor loadings (usually 0 ), and the relations among the factors. In block-diagonal analyses of the MTMM matrix, the trait and error effects are assumed to be additive, and many factor loadings and correlations are assumed to be 0 ; if these assumptions are false, the model is misspecified. Current thought about fixed values is that population values will be close, but not exactly equal, to the assumed fixed values (Coovert, Penner, \& MacCallum, 1990; Widaman, 1985, p. 4). In the current context, it is unlikely that the factor loadings assumed to be 0 are exactly 0 in the population, but they may be so close to 0 as to be practically unimportant.

\section{Problems in Published Matrices}

The block-diagonal model must be applied successfully to data of substantive interest to psychologists in order to prove useful. This study followed Wothke's $(1984,1987)$ example by gathering 18 published MTMM matrices that were based on at least three traits and three methods. These matrices varied in the number of traits, methods, sample size, and constructs measured, and each matrix was fit to the block-diagonal model with LISREL VI (Jöreskog \& Sörbom, 1984).

The quality of each solution was evaluated in several ways.

1. The LISREL output was inspected for identification warnings. If the program printed a warning, the model was considered unidentified for the data at hand, and no further evaluation was done.

2. Each solution was checked for convergence. Convergence is achieved if the program achieves minimal improvement in parameter estimates in less than 250 iterations. If the program terminated after 250 iterations, or 
if the program stopped and printed a message that serious computational problems had been encountered, the program was considered not to have converged.

3. The solution was checked for admissibility. A solution was inadmissible if any of the parameter estimates took theoretically outof-bounds values. This would involve correlations greater than 1 in absolute value, loadings greater than 1 in absolute value, or negative error variances, or would occur if the matrix of factor correlations was not positive definite, even though none of the correlations individually were greater than 1 in absolute value. (All of the analyses were done with correlation matrices as input and with factor variances set to 1.)

4. The fit of the model to the data was checked by examining $\chi^{2}$ relative to its degrees of freedom $(d f)$.

Table 2 shows that 3 of the 18 solutions presented showed identification warnings, 12 failed to converge, and 17 were not admissible. In each of 17 cases there were either problems with the uniqueness matrices (negative error variances), the factor intercorrelations (not positive definite, or factor correlations greater than 1 in absolute value), or factor loadings greater than 1 in absolute value. Only one matrix converged and yielded an admissible solution (Marsh \& Hocevar, 1983), although the $\chi^{2}$ was significant. For reasons discussed below, only matrices of order $3 \times 3$ or greater were analyzed. Wothke's (1984) analysis of matrices given two hypothesized method factors showed problems similar to the data in this study.

Ignoring the admissibility criterion, good fit of the data to the model was achieved for a few of the matrices. If the parameters were constrained to theoretical limits, as is done automatically by the program EQS (Bentler, 1985), some of the models could be judged adequate representations of the data based on fit. Inadmissible solutions are strong indications, however, that the model is misspecified (Jöreskog \& Sörbom, 1984; Wothke, 1987).
The results of the application of the model to real data are disturbing. Assuming that the blockdiagonal model is a proper representation of the data, it is unlikely that the program would generate inadmissible solutions to so many matrices by chance. If only those matrices with sample sizes larger than 200 are considered, there are eight matrices. Of these eight, only two converged, and for one of these the solution was inadmissible. Sampling error, therefore, does not appear to be a good explanation of the current results.

\section{Simulations: Identification}

\section{Method}

If sampling error fails to account for estimation problems in the application of the blockdiagonal model, then there are two alternate explanations for the troubling results: identification problems and specification error. Simulated data were used to assess whether these problems were likely to be explanations of estimation problems, such as those shown in Table 2.

A population correlation matrix was generated by (1) selecting values of $\boldsymbol{\Lambda}$ and $\boldsymbol{\Phi}$ ( $\Theta$ values were determined by squaring the appropriate loadings in $\Lambda$ and subtracting their sum from 1), and (2) computing a population matrix from Equation 1. The matrix computations were done by SAS PROC MATRIX (SAS, 1982), and the input matrices were rounded to six digits after the decimal point.

The population matrix was input to LISREL VI (Jöreskog \& Sörbom, 1984), which estimated the parameters of the model. When the model is identified, LISREL will recover the parameters of the model (within rounding error), and the model will fit perfectly-that is, the reproduced correlation matrix from the parameter estimates will exactly equal the input population matrix. If the model is not identified, one or more parameter estimates will not equal the proper parameter. Lack of identification can also be shown by fixing some parameter estimates to different values over different runs, and showing 
Table 2

Results of the Analyses of 18 MTMM Matrices

\begin{tabular}{|c|c|c|c|c|c|c|c|}
\hline \multirow[b]{2}{*}{ Authors } & \multicolumn{2}{|c|}{ Number of } & \multirow[b]{2}{*}{$N$} & \multirow{2}{*}{$\begin{array}{l}\text { Conver- } \\
\text { gence }\end{array}$} & \multirow{2}{*}{$\begin{array}{l}\text { Admis- } \\
\text { sible }\end{array}$} & \multirow[b]{2}{*}{$\chi^{2}$} & \multirow[b]{2}{*}{$d f$} \\
\hline & Traits & Methods & & & & & \\
\hline Arora $(1982)$ & 3 & 3 & 96 & $\mathbf{N}$ & $\mathrm{N}^{\mathrm{a}, \mathrm{b}}$ & 403.9 & 12 \\
\hline Dickenson \& Tice (1973) & 3 & 3 & 149 & c & - & - & - \\
\hline Flamer (1983), 1 & 3 & 3 & 105 & c & - & - & - \\
\hline Flamer (1983), 2 & 3 & 3 & 105 & c & - & - & - \\
\hline Karst \& Most (1973) & 3 & 3 & 80 & $\mathbf{N}$ & $\mathrm{N}^{\mathrm{a}, \mathrm{b}}$ & 3892.2 & 12 \\
\hline Lawler (1967) & 3 & 3 & 113 & $\mathbf{N}$ & $\mathbf{N}^{a, b}$ & 5580.6 & 12 \\
\hline Marsh \& Hocevar (1988) & 3 & 3 & 319 & $\mathrm{~N}$ & $\mathbf{N}^{b}$ & 1655.8 & $300^{\mathrm{d}}$ \\
\hline Meier (1984) & 3 & 3 & 300 & $\mathbf{N}$ & $\mathbf{N}^{\mathrm{b}}$ & 11.5 & 12 \\
\hline Shepherd (1977) & 3 & 3 & 487 & $\mathbf{N}$ & $\mathbf{N}$ & 1688.9 & 12 \\
\hline Kothandapani (1971) & 3 & 4 & 100 & $\mathbf{Y}$ & $\mathrm{N}^{\mathrm{a}}$ & 53.1 & 33 \\
\hline Ostrom (1969) & 3 & 4 & 189 & $\mathbf{Y}$ & $N^{2}$ & 21.7 & 33 \\
\hline Farh et al. (1984) & 4 & 3 & 406 & $\mathbf{N}$ & $N^{a, b}$ & -645.1 & 33 \\
\hline Dunham et al. (1977) & 4 & 4 & 622 & $\mathbf{Y}$ & $\mathrm{N}^{\mathrm{a}}$ & 349.8 & 76 \\
\hline Jackson (1975) & 4 & 5 & 480 & $\mathbf{N}$ & $N^{a}$ & 410.2 & 134 \\
\hline \multicolumn{8}{|l|}{ Borgatta (from Campbell \& } \\
\hline Fiske, 1959) & 5 & 3 & 125 & $\mathbf{N}$ & $N^{a, b}$ & 100.5 & 62 \\
\hline \multicolumn{8}{|l|}{ Carroll (from Campbell \& } \\
\hline Fiske, 1959) & 5 & 3 & 110 & $\mathbf{Y}$ & $\mathbf{N}^{\mathrm{b}}$ & 112.5 & 62 \\
\hline \multicolumn{8}{|l|}{ Kelly \& Fiske (from } \\
\hline Campbell \& Fiske, 1959) & 5 & 3 & 124 & $\mathbf{Y}$ & $\mathbf{N}^{\mathrm{b}}$ & 57.5 & 62 \\
\hline Marsh \& Hocevar (1983) & 9 & 4 & 316 & $\mathbf{Y}$ & $\mathbf{Y}$ & 684.4 & 516 \\
\hline
\end{tabular}

${ }^{\mathrm{a}} \Theta$ not positive definite.

${ }^{b} \Phi$ not positive definite.

'One or more parameters not identified.

'This matrix was $27 \times 27$; it was a higher-order CFA with three methods, three traits, and three manifest indicators for each trait and method.

that each of the different solutions produces the same population matrix.

Each time an unidentified model was discovered, at least three (and as many as 20) different sets of parameters were used to construct a population matrix in order to confirm that the problem was due to the model rather than the particular set of parameters. Population parameters for the factor loadings were chosen between .20 and .80 to avoid empirical identification problems common to all CFA models. For all runs, factor variances were fixed at 1.0. Matrices analyzed had three traits and three methods, four traits and two methods, and five traits and two methods.

\section{Results}

Some population matrices were recovered, which suggests that the model was identified, although other population matrices could not be recovered, which suggests empirical identification problems. LISREL initial (two-stage least squares) estimates were uniformly poor, with estimates of factor correlations greater than 1 in every case.

$3 \times 3$ matrices. The three methods by three traits models usually allowed LISREL to recover the proper parameters in all but three general cases. These three cases represent possible empirical identification problems. The consequence of empirical identification is that the model fails to yield proper estimates of population values, and cannot be interpreted.

Table 1 shows a general representation of the three-trait by three-method block-diagonal MTMM analysis; there are three cases that can be considered in such a matrix. Case 1 is indicated 
as loadings/correlations $\mathrm{A}=\mathrm{B}=\mathrm{C}, \mathrm{D}=$ $\mathrm{E}=\mathrm{F}, \mathrm{G}=\mathrm{H}=\mathrm{I}, \mathrm{J}=\mathrm{K}=\mathrm{L}, \mathrm{M}=\mathrm{N}=$ $\mathrm{O}$, and $\mathrm{P}=\mathrm{Q}=\mathrm{R}$. Proof is given in Wothke (1984) that Case 1 is unidentified. Should such a pattern hold in the population, data (the population correlation matrix) could not be used to estimate the parameters because there are an infinite number of equally good solutions to the problem.

Table 3 shows the results of ten different solutions. The capital letters in the first column correspond to the parameters in the matrices in Table 1; the numbers in Table 3 correspond to the parameters actually used in Equation 1 to compute a correlation matrix. In nine solutions LISREL warned that at least one parameter might be unidentified. Three of the solutions failed to converge, and only one solution was admissible. In no case was LISREL able to recover the correct parameters.

Case 2 is represented as $\mathrm{A}=\mathrm{B}=\mathrm{C}=\mathrm{D}=$ $\mathrm{E}=\mathrm{F}=\mathrm{G}=\mathrm{H}=\mathrm{I}$, and $\mathrm{S}=\mathrm{T}=\mathrm{U}$. LISREL was rarely able to recover the correct parameter sets in this case. Case 3 is represented as $\mathbf{J}=\mathrm{K}=\mathrm{L}=\mathrm{M}=\mathrm{N}=\mathrm{O}=\mathrm{P}=\mathrm{Q}=$ $R$, and $V=W=X$. Results of five Case 2 solutions and five Case 3 solutions are shown in Table 4. Table 4 shows numerous estimation problems, including identification warnings, lack of convergence, and inadmissible solutions. A comparison of solutions 9 and 10 in Table 4 suggests that the particular values of the parameters determine whether LISREL can recover the correct set of parameters.

Two-method matrices. Like the $3 \times 3$ matrices, the two-method matrices were subject to empirical identification problems. The twomethod matrices appeared to be subject to many more such problems than did matrices with greater numbers of factors; an example is presented in detail below. Table 5 shows the parameters used to generate the population matrix.

In the initial run, the program failed to converge and serious problems were encountered during minimization. Other warnings were printed, the most serious being that $\boldsymbol{\Lambda}(2,5)$ may not be
Table 3

Parameter Values Used for Ten Case 1 Analyses of $3 \mathrm{~T} \times 3 \mathrm{M}$ Matrices, and Results and Problems From Each Solution (Ident Warn = Program Printed a Warning that One or More Parameters Might Be Unidentified; - = Negative $\chi^{2}$; Parm Equal $=$ Program Recovered the Proper Parameters) (Decimal Points Omitted)

\begin{tabular}{|c|c|c|c|c|c|c|c|c|c|c|}
\hline \multirow[b]{2}{*}{ Parameter } & \multicolumn{10}{|c|}{ Parameter Values } \\
\hline & 1 & 2 & 3 & 4 & 5 & 6 & 7 & 8 & 9 & 10 \\
\hline A & 70 & 73 & 43 & 70 & 79 & 22 & 22 & 70 & 52 & 52 \\
\hline B & 70 & 73 & 43 & 70 & 79 & 22 & 22 & 70 & 52 & 52 \\
\hline $\mathrm{C}$ & 70 & 73 & 43 & 70 & 79 & 22 & 22 & 70 & 52 & 52 \\
\hline D & 50 & 75 & 54 & 60 & 78 & 23 & 23 & 70 & 23 & 23 \\
\hline E & 50 & 75 & 54 & 60 & 78 & 23 & 23 & 70 & 23 & 23 \\
\hline $\mathrm{F}$ & 50 & 75 & 54 & 60 & 78 & 23 & 23 & 70 & 23 & 23 \\
\hline $\mathrm{G}$ & 30 & 62 & 65 & 50 & 77 & 32 & 32 & 70 & 82 & 82 \\
\hline $\mathrm{H}$ & 30 & 62 & 65 & 50 & 77 & 32 & 32 & 70 & 82 & 82 \\
\hline I & 30 & 62 & 65 & 50 & 77 & 32 & 32 & 70 & 82 & 82 \\
\hline $\mathbf{J}$ & 20 & 21 & 42 & 30 & 21 & 70 & 70 & 20 & 50 & 50 \\
\hline K & 20 & 21 & 42 & 30 & 21 & 70 & 70 & 20 & 50 & 50 \\
\hline $\mathrm{L}$ & 20 & 21 & 42 & 30 & 21 & 70 & 70 & 20 & 50 & 50 \\
\hline M & 40 & 32 & 31 & 40 & 23 & 80 & 80 & 20 & 40 & 40 \\
\hline $\mathrm{N}$ & 40 & 32 & 31 & 40 & 23 & 80 & 80 & 20 & 40 & 40 \\
\hline $\mathrm{O}$ & 40 & 32 & 31 & 40 & 23 & 80 & 80 & 20 & 40 & 40 \\
\hline $\mathbf{P}$ & 30 & 41 & 25 & 35 & 22 & 60 & 60 & 20 & 30 & 30 \\
\hline $\mathrm{Q}$ & 30 & 41 & 25 & 35 & 22 & 60 & 60 & 20 & 30 & 30 \\
\hline $\mathbf{R}$ & 30 & 41 & 25 & 35 & 22 & 60 & 60 & 20 & 30 & 30 \\
\hline $\mathrm{S}$ & 80 & 10 & 31 & 30 & 41 & 70 & 10 & 00 & 80 & 10 \\
\hline $\mathrm{T}$ & 70 & 30 & 28 & 40 & 42 & 75 & 05 & 00 & 85 & 25 \\
\hline $\mathrm{U}$ & 75 & 20 & 22 & 50 & 43 & 80 & 08 & 00 & 90 & 30 \\
\hline V & 29 & 20 & 19 & 30 & 33 & 50 & 60 & 00 & 40 & 40 \\
\hline W & 20 & 40 & 33 & 10 & 31 & 61 & 61 & 00 & 42 & 42 \\
\hline $\mathrm{X}$ & 25 & 30 & 27 & 20 & 32 & 48 & 78 & 00 & 38 & 38 \\
\hline \multicolumn{11}{|c|}{ Results and Problems $(Y=$ Yes, $N=$ No) } \\
\hline Ident Warn & $\mathrm{Y}$ & $\mathbf{N}$ & $\mathrm{Y}$ & $\mathrm{Y}$ & $\mathrm{Y}$ & $\mathrm{Y}$ & $\mathrm{Y}$ & $\mathrm{Y}$ & $\mathrm{Y}$ & $\mathbf{Y}$ \\
\hline Converged & $\mathrm{Y}$ & Y & $Y$ & $Y$ & $\mathbf{N}$ & $\mathbf{N}$ & $\mathbf{N}$ & $\mathbf{Y}$ & $Y$ & $\mathbf{Y}$ \\
\hline Admissible & $\mathrm{N}$ & $\mathbf{N}$ & $\mathbf{N}$ & $\mathbf{N}$ & $\mathbf{N}$ & $\mathbf{N}$ & $\mathbf{N}$ & $\mathbf{N}$ & $\mathrm{N}$ & $\mathbf{Y}$ \\
\hline$\chi^{2} / d f$ & 0 & 0 & 0 & 0 & - & - & - & 1 & 0 & 0 \\
\hline Parm Equal & $\mathrm{N}$ & $\mathbf{N}$ & $\mathrm{N}$ & $\mathrm{N}$ & $\mathrm{N}$ & $\mathbf{N}$ & $\mathbf{N}$ & $\mathbf{N}$ & $\mathrm{N}$ & $\mathbf{N}$ \\
\hline
\end{tabular}

identified. During a subsequent run, $\boldsymbol{\Lambda}(2,5)$ was fixed to its population value (.33). The program converged after 30 iterations, and gave the maximum likelihood estimates shown in Table 5. $\chi^{2}$ with $6 d f$ was 0 , the goodness-of-fit and adjusted goodness-of-fit indices were 1 , and the root mean square residual was 0 . The largest modification index was .002 for element $\boldsymbol{\Lambda}(2,5)$, which was set to its correct population value. No warning messages were printed, but the parameter es- 
Table 4

Parameter Values Used for Five Case 2 and Five Case 3 Analyses of $3 \mathrm{~T} \times 3 \mathrm{M}$ Matrices, and

Results and Problems From Each Solution (Ident Warn $=$ Program Printed a Warning that One or More Parameters Might Be Unidentified;

- = Negative $\chi^{2}$; Parm Equal $=$ Program Recovered the Proper Parameters) (Decimal Points Omitted)

\begin{tabular}{|c|c|c|c|c|c|c|c|c|c|c|}
\hline \multirow[b]{3}{*}{ Parameter } & \multicolumn{10}{|c|}{ Parameter Values } \\
\hline & \multicolumn{5}{|c|}{ Case 2} & \multicolumn{5}{|c|}{ Case 3} \\
\hline & 1 & 2 & 3 & 4 & 5 & 6 & 7 & 8 & 9 & 10 \\
\hline A & 70 & 65 & 79 & 79 & 50 & 79 & 69 & 29 & 45 & 45 \\
\hline B & 70 & 65 & 79 & 79 & 50 & 78 & 58 & 58 & 54 & 54 \\
\hline $\mathrm{C}$ & 70 & 65 & 79 & 79 & 50 & 77 & 77 & 37 & 59 & 59 \\
\hline $\mathrm{D}$ & 70 & 65 & 79 & 79 & 50 & 69 & 59 & 29 & 59 & 59 \\
\hline $\mathrm{E}$ & 70 & 65 & 79 & 79 & 50 & 73 & 63 & 43 & 55 & 55 \\
\hline $\mathrm{F}$ & 70 & 65 & 79 & 79 & 50 & 59 & 49 & 29 & 49 & 49 \\
\hline $\mathrm{G}$ & 70 & 65 & 79 & 79 & 50 & 59 & 49 & 39 & 77 & 77 \\
\hline $\mathrm{H}$ & 70 & 65 & 79 & 79 & 50 & 72 & 72 & 42 & 72 & 72 \\
\hline I & 70 & 65 & 79 & 79 & 50 & 75 & 65 & 35 & 66 & 66 \\
\hline $\mathbf{J}$ & 25 & 35 & 33 & 33 & 45 & 20 & 33 & 53 & 61 & 50 \\
\hline $\mathbf{K}$ & 27 & 37 & 23 & 23 & 54 & 20 & 33 & 53 & 61 & 50 \\
\hline $\mathbf{L}$ & 29 & 39 & 29 & 39 & 59 & 20 & 33 & 53 & 61 & 50 \\
\hline $\mathbf{M}$ & 31 & 41 & 21 & 41 & 59 & 20 & 33 & 53 & 61 & 50 \\
\hline $\mathbf{N}$ & 27 & 27 & 37 & 47 & 55 & 20 & 33 & 53 & 61 & 50 \\
\hline $\mathrm{O}$ & 19 & 39 & 39 & 39 & 49 & 20 & 33 & 53 & 61 & 50 \\
\hline $\mathbf{P}$ & 42 & 22 & 22 & 22 & 77 & 20 & 33 & 53 & 61 & 50 \\
\hline$Q$ & 44 & 24 & 24 & 44 & 72 & 20 & 33 & 53 & 61 & 50 \\
\hline $\mathrm{R}$ & 40 & 21 & 21 & 21 & 66 & 20 & 33 & 53 & 61 & 50 \\
\hline $\mathbf{S}$ & 30 & 70 & 05 & 40 & 30 & 15 & 05 & 25 & 82 & 00 \\
\hline $\mathrm{T}$ & 30 & 70 & 05 & 40 & 30 & 25 & 55 & 35 & 67 & 10 \\
\hline $\mathrm{U}$ & 30 & 70 & 05 & 40 & 30 & 05 & 65 & 45 & 70 & 05 \\
\hline V & 20 & 20 & 40 & 20 & 10 & 30 & 70 & 25 & 35 & 35 \\
\hline W & 12 & 12 & 30 & 12 & 12 & 30 & 70 & 25 & 35 & 35 \\
\hline $\mathrm{X}$ & 15 & 15 & 35 & 15 & 15 & 30 & 70 & 25 & 35 & 35 \\
\hline \multicolumn{11}{|c|}{ Results and Problems ( $\mathrm{Y}=$ Yes, $\mathrm{N}=\mathrm{No}$ ) } \\
\hline Ident Warn & $\mathbf{Y}$ & $\mathbf{N}$ & $\mathbf{N}$ & $\mathbf{Y}$ & $\mathbf{N}$ & $\mathbf{Y}$ & $\mathbf{Y}$ & $\mathbf{Y}$ & $\mathbf{N}$ & $\mathbf{N}$ \\
\hline Converged & $\mathbf{N}$ & $\mathbf{Y}$ & $\mathbf{N}$ & $\mathbf{N}$ & $\mathbf{Y}$ & $\mathbf{N}$ & $\mathbf{N}$ & $\mathbf{N}$ & $\mathbf{N}$ & $\mathbf{Y}$ \\
\hline Admissible & $\mathbf{N}$ & $\mathbf{N}$ & $\mathbf{N}$ & $\mathrm{N}$ & $\mathbf{Y}$ & $\mathrm{N}$ & $\mathbf{N}$ & $\mathbf{N}$ & $\mathbf{Y}$ & $\mathbf{Y}$ \\
\hline$\chi^{2} / d f$ & - & 0 & 16 & - & 0 & - & - & - & 0 & 0 \\
\hline Parm Equal & $\mathbf{N}$ & $\mathrm{N}$ & $\mathbf{N}$ & $\mathbf{N}$ & $\mathbf{Y}$ & $\mathrm{N}$ & $\mathbf{N}$ & $\mathbf{N}$ & $\mathbf{N}$ & $\mathbf{Y}$ \\
\hline
\end{tabular}

timates were generally distant from their population values.

Table 6 shows the hypothesized factor structure of a $5 \mathrm{~T} \times 2 \mathrm{M}$ MTMM matrix. The structure of the $4 \mathrm{~T} \times 2 \mathrm{M}$ MTMM matrix is given by eliminating rows for $X_{5}, X_{10}$, and $T_{5}$, so that parameters I, O, J, T, AA, BB, CC, and DD are not estimated. The results of ten $4 \mathrm{~T} \times 2 \mathrm{M}$ so- lutions are shown in Table 7 (letters in the first column correspond to the parameters in the matrices of Table 6). LISREL recovered the correct set of parameters in half of the solutions. Solution 10 is of particular concern, because the program ran without estimation problems but still failed to recover the correct set of parameters.

Results of the $5 \mathrm{~T} \times 2 \mathrm{M}$ solutions are shown in Table 8 (letters in the first column correspond to the parameters in Table 6). Correct recovery of parameters was achieved for 3 of 10 solutions. There were estimation problems in $70 \%$ of the solutions.

The Case 1, 2, and 3 problems all have some parameters equal in the population matrix. This would be unlikely to happen in practice. In most $3 \mathrm{~T} \times 3 \mathrm{M}$ solutions where the population parameters are all different, LISREL recovered the proper parameters (for examples, see the section on minor misspecification below). Some parameter sets, however, were not recovered by LISREL even though all the parameters were different. Three such sets of parameters were

$.55, .66, .81, .64, .74, .73, .40, .44, .50, .38, .44$, $.51, .22, .25, .21, .57, .56, .60, .35, .28, .36, .10$, $.12, .15$,

$.88, .78, .81, .89, .77, .83, .90, .76, .82, .20, .22$, $.21, .24, .25, .26, .31, .30, .29, .50 .55, .56, .22$, $.39, .38$,

$.78, .79, .71, .89, .77, .73, .60, .76, .82, .34, .22$, $.21, .24, .25, .46, .31, .30, .29, .30, .25, .36, .22$, $.39, .38$,

where the numbers in each set correspond to the letters A through $\mathrm{X}$ in Table 1, respectively. None of these three solutions converged, and two of the three solutions were inadmissible. Therefore, should the program print identification or other estimation warnings for a $3 \mathrm{~T} \times 3 \mathrm{M}$ analysis, it would be inappropriate to disregard them.

\section{Simulations: Specification Errors}

If sampling error and identification problems do not explain the results in Table 2, specification error may be a likely explanation. To examine 
Table 5

Population Values (P) and Estimates (E) in an Unidentified Problem (All Parameters with Values 0 or 1 Were Fixed)

\begin{tabular}{|c|c|c|c|c|c|c|c|c|c|c|c|c|}
\hline \multirow{3}{*}{$\begin{array}{c}\text { Observed } \\
\text { Variable }\end{array}$} & \multicolumn{8}{|c|}{ Trait Factors } & \multicolumn{4}{|c|}{ Method Factors } \\
\hline & \multicolumn{2}{|c|}{$\mathbf{T}_{1}$} & \multicolumn{2}{|c|}{$\mathrm{T}_{2}$} & \multicolumn{2}{|c|}{$\mathrm{T}_{3}$} & \multicolumn{2}{|c|}{$T_{4}$} & \multicolumn{2}{|c|}{$\mathrm{M}_{1}$} & \multicolumn{2}{|c|}{$\mathbf{M}_{2}$} \\
\hline & $P$ & $\mathrm{E}$ & $\mathbf{P}$ & $\mathbf{E}$ & $\mathbf{P}$ & $\mathrm{E}$ & $\mathbf{P}$ & $\mathrm{E}$ & $\mathrm{P}$ & $\mathrm{E}$ & $\mathbf{P}$ & $\mathbf{E}$ \\
\hline \multicolumn{13}{|c|}{$\bar{\Lambda}$ (Factor Loadings) } \\
\hline $\mathrm{X}_{\mathrm{I}}$ & .70 & .61 & 0.0 & & 0.0 & & 0.0 & & .30 & .31 & 0.0 & \\
\hline $\mathrm{X}_{2}$ & 0.0 & & .72 & .65 & 0.0 & & 0.0 & & .33 & .33 & 0.0 & \\
\hline $\mathrm{X}_{3}$ & 0.0 & & 0.0 & & .74 & .69 & 0.0 & & .37 & .36 & 0.0 & \\
\hline $\mathrm{X}_{4}$ & 0.0 & & 0.0 & & 0.0 & & .68 & .64 & .35 & .35 & 0.0 & \\
\hline$X_{5}$ & .60 & .77 & 0.0 & & 0.0 & & 0.0 & & 0.0 & & .40 & .20 \\
\hline $\mathrm{X}_{6}$ & 0.0 & & .64 & .78 & 0.0 & & 0.0 & & 0.0 & & .35 & .15 \\
\hline $\mathbf{X}_{7}$ & 0.0 & & 0.0 & & .67 & .79 & 0.0 & & 0.0 & & .33 & .13 \\
\hline $\mathbf{X}_{\mathrm{B}}$ & 0.0 & & 0.0 & & 0.0 & & .69 & .79 & 0.0 & & .31 & .09 \\
\hline \multicolumn{13}{|c|}{$\Phi$ (Factor Correlations) } \\
\hline$T_{1}$ & 1.0 & & & & & & & & & & & \\
\hline $\mathrm{T}_{2}$ & .30 & .37 & 1.0 & & & & & & & & & \\
\hline $\mathrm{T}_{3}$ & .30 & .37 & .30 & .36 & 1.0 & & & & & & & \\
\hline $\mathrm{T}_{4}$ & .32 & .39 & .32 & .38 & .35 & .40 & 1.0 & & & & & \\
\hline $\mathbf{M}_{1}$ & 0.0 & & 0.0 & & 0.0 & & 0.0 & & 1.0 & & & \\
\hline $\mathbf{M}_{2}$ & 0.0 & & 0.0 & & 0.0 & & 0.0 & & .25 & -.37 & 1.0 & \\
\hline
\end{tabular}

the effects of specification errors, two small simulations were run. The first simulation examined the effects of serious misspecification, and the second examined the effects of minor misspecification.

\section{Serious Misspecification}

Method. A $3 \times 3$ block-diagonal model was fit to data from 20 populations with only trait factors. A model of uncorrelated traits was tried first, and then five models of correlated traits, seven of orthogonal traits with errant loadings (i.e., variables loaded on more than one trait), and seven of correlated traits with errant loadings were tried. Magnitudes of parameter values, the number of correlated traits, and the number, magnitude, and location of errant loadings varied across runs.

Results. Results of the analyses are shown in Table 9. The magnitude of errant loadings varied from .1 to .65 . Technically, the first six solutions were not misspecified because there were no errant loadings; they are restrictive examples of the Case 3 problem in which all the values are
0 . Because the method factor loadings and correlations were 0 in the population, LISREL should recover the 0 loadings, although the correct loadings may not be recoverable because of empirical identification problems (Dillon et al., 1987). LISREL was unable to recover the population parameters in any of the first six solutions, although one solution was admissible.

For the last 14 solutions, LISREL was unable to recover the proper population values because the problems were misspecified. Solutions to all the latter problems were inadmissible. Identification warnings were printed for 11 solutions, and eight analyses failed to converge.

None of the solutions yielded a large $\chi^{2}$ value, although in four cases the $\chi^{2}$ value was negative. In fact, half the matrices yielded perfect fit, and three of the remaining matrices fit well. The misspecification results strongly suggest that goodness of fit cannot be relied on in the presence of computational problems. As Jöreskog and Sörbom (1984, p. I. 32) argued, computational problems can indicate misspecification. These results demonstrate that even severe misspecifi- 
Table 6

Block-Diagonal Model With Five Traits $\left(T_{1}, T_{2}, T_{3}, T_{4}, T_{5}\right)$ and Two Methods $\left(M_{1}, M_{2}\right)$

\begin{tabular}{|c|c|c|c|c|c|c|c|}
\hline \multirow{2}{*}{$\begin{array}{c}\text { Observed } \\
\text { Variable }\end{array}$} & \multicolumn{5}{|c|}{ Trait Factor } & \multicolumn{2}{|c|}{$\begin{array}{l}\text { Method } \\
\text { Factor }\end{array}$} \\
\hline & $\mathrm{T}_{1}$ & $T_{2}$ & $\mathrm{~T}_{3}$ & $T_{4}$ & $\mathbf{T}_{5}$ & $\mathbf{M}_{1}$ & $\mathbf{M}_{2}$ \\
\hline \multicolumn{8}{|c|}{$\mathbf{\Lambda}$ (Factor Loadings) } \\
\hline $\mathrm{X}_{1}$ & A & 0.0 & 0.0 & 0.0 & 0.0 & $\mathbf{K}$ & 0.0 \\
\hline $\mathrm{X}_{2}$ & 0.0 & $\mathrm{C}$ & 0.0 & 0.0 & 0.0 & $\mathrm{~L}$ & 0.0 \\
\hline $\mathbf{X}_{3}$ & 0.0 & 0.0 & E & 0.0 & 0.0 & $\mathbf{M}$ & 0.0 \\
\hline$X_{4}$ & 0.0 & 0.0 & 0.0 & $\mathrm{G}$ & 0.0 & $\mathbf{N}$ & 0.0 \\
\hline$X_{s}^{4}$ & 0.0 & 0.0 & 0.0 & 0.0 & I & $\mathrm{O}$ & 0.0 \\
\hline$X_{6}$ & B & 0.0 & 0.0 & 0.0 & 0.0 & 0.0 & $\mathbf{P}$ \\
\hline$X_{7}$ & 0.0 & D & 0.0 & 0.0 & 0.0 & 0.0 & $\mathbf{Q}$ \\
\hline $\mathrm{X}_{8}$ & 0.0 & 0.0 & $\mathrm{~F}$ & 0.0 & 0.0 & 0.0 & $\mathbf{R}$ \\
\hline $\mathrm{X}_{9}$ & 0.0 & 0.0 & 0.0 & $\mathbf{H}$ & 0.0 & 0.0 & $\mathrm{~S}$ \\
\hline$X_{10}$ & 0.0 & 0.0 & 0.0 & 0.0 & $\mathbf{J}$ & 0.0 & $\mathrm{~T}$ \\
\hline \multicolumn{8}{|c|}{$\Phi$ (Factor Correlations) } \\
\hline$T_{1}$ & 1.0 & & & & & & \\
\hline $\mathrm{T}_{2}$ & $\mathbf{U}$ & 1.0 & & & & & \\
\hline $\mathrm{T}_{3}$ & V & W & 1.0 & & & & \\
\hline $\mathrm{T}_{4}$ & $\mathrm{X}$ & $\mathrm{Y}$ & $\mathbf{Z}$ & 1.0 & & & \\
\hline$T_{5}$ & AA & BB & $\mathrm{CC}$ & DD & 1.0 & & \\
\hline $\mathbf{M}_{\mathbf{1}}$ & 0.0 & 0.0 & 0.0 & 0.0 & 0.0 & 1.0 & \\
\hline $\mathrm{M}_{2}$ & 0.0 & 0.0 & 0.0 & 0.0 & 0.0 & EE & 1.0 \\
\hline
\end{tabular}

cation can yield good fit; good fit must be obtained in the absence of computational problems for a model to be acceptable as supported. Marsh (1989) also reached this conclusion, although it was based on another rationale.

\section{Minor Misspecification}

$3 \times 3$ MTMM matrices were generated that fit the hypothesized model perfectly, except that the loadings and correlations assumed to be 0 were not 0 in the population matrix. Three different sets of parameters were chosen that were used in Equation 1 to create three (correctly specified) population matrices. To check for identification problems, each of the three population matrices was submitted to LISREL. The parameters for each of the three matrices were recovered perfectly, which suggests that the parameters were identified; these three sets of parameters are referred to as "correct" parameters below.

These three sets of correct parameters were $.72, .61, .65, .61, .71, .64, .73, .62, .63, .25, .25$,
$.35, .32, .31, .41, .42, .31, .32, .29, .30, .31, .29$, $.32, .33$,

$.52, .52, .54, .23, .24, .22, .72, .62, .64, .50, .47$, $.48, .49, .37, .38, .29, .20, .22, .80, .85, .90, .40$, $.42, .38$,

$.88, .56, .89, .80, .66, .83, .77, .59, .50, .22, .30$, $.31, .23, .45, .25, .27, .26, .60, .60, .66, .62, .10$, $.12, .15$,

where the numbers in each set correspond to the letters $\mathrm{A}$ through $\mathrm{X}$ in Table 1, respectively.

\section{Table 7}

Parameter Values Used for Ten Analyses of $4 \mathrm{~T} \times 2 \mathrm{M}$ Matrices, and Results and Problems From Each Solution (Ident Warn = Program Printed a Warning that One or More Parameters Might Be Unidentified; - = Negative $\chi^{2}$; Parm Equal $=$ Program Recovered the Proper Parameters) (Decimal Points Omitted)

\begin{tabular}{|c|c|c|c|c|c|c|c|c|c|c|}
\hline \multirow[b]{2}{*}{ Parameter } & \multicolumn{10}{|c|}{ Parameter Values } \\
\hline & 1 & 2 & 3 & 4 & 5 & 6 & 7 & 8 & & 10 \\
\hline $\mathbf{A}$ & 77 & 77 & 77 & 76 & 67 & 67 & 37 & 26 & 66 & 67 \\
\hline B & 50 & 50 & 50 & 51 & 65 & 65 & 45 & 81 & & 65 \\
\hline $\mathrm{C}$ & 61 & 60 & 60 & 62 & 55 & 55 & 35 & 62 & & 55 \\
\hline D & 64 & 64 & 64 & 72 & 63 & 63 & 33 & 72 & & 63 \\
\hline $\mathrm{E}$ & 63 & 62 & 62 & 63 & 70 & 70 & 27 & 63 & 53 & 70 \\
\hline $\mathrm{F}$ & 42 & 40 & 40 & 43 & 75 & 75 & 25 & 43 & 53 & 75 \\
\hline $\mathrm{G}$ & 60 & 60 & 60 & 68 & 55 & 55 & 55 & 48 & 48 & 55 \\
\hline $\mathrm{H}$ & 54 & 50 & 50 & 59 & 64 & 44 & 44 & 59 & 59 & 64 \\
\hline $\mathbf{K}$ & 22 & 52 & 522 & 20 & 31 & 51 & 51 & 60 & 60 & 31 \\
\hline $\mathrm{L}$ & 33 & 42 & 42 & 33 & 22 & 42 & 42 & 33 & & 22 \\
\hline $\bar{M}$ & 21 & 22 & 22 & 22 & 32 & 72 & 72 & 23 & 53 & 32 \\
\hline $\mathbf{N}$ & 24 & 24 & 24 & 40 & 24 & 24 & 24 & 55 & 55 & 24 \\
\hline $\mathbf{P}$ & 40 & 40 & 40 & 40 & 31 & 51 & 51 & 20 & 55 & 31 \\
\hline$Q$ & 36 & 35 & 35 & 32 & 35 & 65 & 65 & 32 & 42 & 35 \\
\hline $\mathbf{R}$ & 32 & 33 & 33 & 31 & 33 & 73 & 73 & 51 & 51 & 33 \\
\hline$S$ & 54 & 54 & 54 & 55 & 34 & 54 & 54 & 55 & 55 & 34 \\
\hline $\mathrm{U}$ & 62 & 60 & 30 & 23 & 52 & 30 & 30 & 70 & 70 & 10 \\
\hline V & 64 & 60 & 20 & 37 & 44 & 20 & 20 & 10 & 60 & 10 \\
\hline W & 65 & 65 & 35 & 24 & 58 & 35 & 35 & 15 & 55 & 10 \\
\hline$X$ & 52 & 52 & 22 & 13 & 52 & 22 & 22 & 13 & 63 & 10 \\
\hline $\mathrm{Y}$ & 63 & 63 & 33 & 35 & 43 & 33 & 33 & 12 & 72 & 10 \\
\hline Z & 59 & 59 & 29 & 27 & 44 & 29 & 29 & 87 & 87 & 10 \\
\hline$\overline{\mathrm{EE}}$ & 27 & 35 & 40 & 55 & 15 & 15 & 15 & 33 & 58 & 15 \\
\hline \multicolumn{11}{|c|}{ Results and Problems $(\mathrm{Y}=\mathrm{Yes}, \mathrm{N}=\mathrm{No})$} \\
\hline Ident Warn & $\mathbf{N}$ & $\mathrm{N}$ & $N$ & $\mathbf{N}$ & $\mathbf{N}$ & $\mathbf{Y}$ & $\mathbf{Y}$ & $\mathbf{N}$ & $\mathbf{N}$ & $\mathbf{N}$ \\
\hline Converged & $\mathrm{Y}$ & $\mathrm{N}$ & $\mathrm{Y}$ & $Y$ & $Y$ & $\mathrm{~N}$ & $N$ & $\mathrm{Y}$ & $\mathbf{Y}$ & $Y$ \\
\hline Admissible & $\mathbf{N}$ & $\mathbf{N}$ & $\mathrm{Y}$ & $\mathbf{Y}$ & $\mathbf{Y}$ & $\mathbf{N}$ & $\mathbf{N}$ & $\mathrm{Y}$ & $\mathbf{Y}$ & $\mathbf{Y}$ \\
\hline$\chi^{2} / d f$ & 0 & 0 & 0 & 0 & 0 & - & - & 0 & 0 & 0 \\
\hline Parm Equal & $\mathbf{N}$ & $\mathbf{N}$ & $\mathrm{Y}$ & $\mathbf{Y}$ & Y & $\mathrm{N}$ & $\mathbf{N}$ & $\mathrm{Y}$ & & \\
\hline
\end{tabular}


Table 8

Parameter Values Used for Ten Analyses of $5 \mathrm{~T} \times 2 \mathrm{M}$ Matrices, and Results and Problems From Each Solution (Ident Warn = Program Printed a Warning that One or More Parameters Might Be Unidentified; - = Negative $\chi^{2}$; Parm Equal $=$ Program Recovered the Proper Parameters) (Decimal Points Omitted)

\begin{tabular}{|c|c|c|c|c|c|c|c|c|c|c|}
\hline \multirow[b]{2}{*}{ Parameter } & \multicolumn{10}{|c|}{ Parameter Values } \\
\hline & 1 & 2 & 3 & 4 & 5 & 6 & 7 & 8 & 9 & 10 \\
\hline $\mathbf{A}$ & 56 & 66 & 66 & 46 & 46 & 20 & 66 & 26 & 26 & 70 \\
\hline B & 66 & 81 & 66 & 36 & 36 & 30 & 81 & 66 & 66 & 30 \\
\hline C & 42 & 82 & 82 & 32 & 32 & 30 & 82 & 22 & 22 & 70 \\
\hline D & 55 & 72 & 55 & 25 & 25 & 28 & 72 & 55 & 55 & 28 \\
\hline E & 63 & 53 & 53 & 63 & 63 & 40 & 53 & 23 & 23 & 73 \\
\hline $\mathbf{F}$ & 63 & 43 & 43 & 33 & 33 & 23 & 53 & 63 & 63 & 23 \\
\hline $\mathrm{G}$ & 58 & 48 & 48 & 28 & 28 & 33 & 48 & 28 & 28 & 63 \\
\hline $\mathrm{H}$ & 69 & 59 & 59 & 29 & 29 & 49 & 59 & 69 & 69 & 49 \\
\hline I & 60 & 70 & 70 & 40 & 40 & 21 & 70 & 20 & 20 & 51 \\
\hline $\mathbf{J}$ & 65 & 55 & 55 & 45 & 45 & 45 & 55 & 65 & 65 & 45 \\
\hline $\mathbf{K}$ & 60 & 60 & 60 & 60 & 60 & 20 & 60 & 60 & 60 & 20 \\
\hline $\mathrm{L}$ & 70 & 30 & 30 & 70 & 70 & 22 & 33 & 70 & 70 & 22 \\
\hline $\mathrm{M}$ & 72 & 50 & 50 & 72 & 72 & 23 & 53 & 72 & 72 & 23 \\
\hline $\mathrm{N}$ & 80 & 40 & 40 & 80 & 80 & 21 & 55 & 80 & 80 & 21 \\
\hline 0 & 71 & 20 & 20 & 71 & 70 & 26 & 50 & 71 & 71 & 26 \\
\hline$P$ & 50 & 50 & 50 & 50 & 50 & 20 & 55 & 50 & 50 & 20 \\
\hline$Q$ & 81 & 40 & 40 & 81 & 80 & 31 & 42 & 81 & 81 & 31 \\
\hline $\mathbf{R}$ & 73 & 60 & 60 & 73 & 70 & 43 & 51 & 73 & 73 & 43 \\
\hline S & 68 & 20 & 20 & 68 & 68 & 48 & 55 & 68 & 68 & 48 \\
\hline$T$ & 69 & 30 & 30 & 69 & 70 & 59 & 40 & 69 & 69 & 59 \\
\hline U & 21 & 21 & 21 & 51 & 51 & 15 & 70 & 71 & 81 & 35 \\
\hline V & 22 & 22 & 22 & 52 & 52 & 10 & 60 & 72 & 82 & 20 \\
\hline W & 29 & 31 & 31 & 51 & 51 & 05 & 55 & 75 & 85 & 35 \\
\hline X & 26 & 24 & 24 & 54 & 54 & 20 & 63 & 26 & 26 & 40 \\
\hline$Y$ & 19 & 23 & 23 & 53 & 53 & 22 & 72 & 19 & 19 & 22 \\
\hline Z & 20 & 30 & 30 & 50 & 50 & 24 & 87 & 20 & 20 & 24 \\
\hline AA & 27 & 27 & 27 & 57 & 57 & 26 & 80 & 27 & 27 & 26 \\
\hline BB & 28 & 28 & 28 & 58 & 58 & 25 & 79 & 28 & 28 & 36 \\
\hline $\mathrm{CC}$ & 23 & 33 & 33 & 53 & 53 & 23 & 78 & 23 & 23 & 36 \\
\hline DD & 24 & 34 & 34 & 54 & 54 & 21 & 81 & 24 & 24 & 31 \\
\hline $\mathrm{EE}$ & 63 & 18 & 18 & 33 & 33 & 11 & 18 & 33 & 63 & 66 \\
\hline \multicolumn{11}{|c|}{ Results and Problems $(\mathrm{Y}=\mathrm{Yes}, \mathrm{N}=\mathrm{No})$} \\
\hline Ident Warn & $\mathbf{N}$ & $\mathrm{N}$ & $\mathrm{N}$ & $\mathrm{N}$ & $\mathrm{N}$ & $\mathrm{Y}$ & $\mathrm{N}$ & $\mathrm{N}$ & $\mathrm{Y}$ & $\mathrm{Y}$ \\
\hline Converged & Y & $\mathbf{Y}$ & $\mathbf{Y}$ & $\mathbf{Y}$ & $\mathbf{N}$ & $\mathrm{N}$ & $\mathbf{N}$ & $\mathrm{N}$ & $\mathbf{N}$ & $\mathrm{N}$ \\
\hline Admissible & $\mathrm{Y}$ & $\mathrm{Y}$ & $\mathbf{Y}$ & $\mathbf{N}$ & $\mathrm{N}$ & $\mathrm{N}$ & $\mathbf{N}$ & $\mathbf{N}$ & $\mathrm{N}$ & $\mathrm{N}$ \\
\hline$\chi^{2} / d f$ & 0 & 0 & 0 & 0 & 0 & - & 0 & 0 & - & - \\
\hline Parm Equal & $\mathrm{Y}$ & $Y$ & $\mathrm{Y}$ & $\mathbf{N}$ & $\mathrm{N}$ & $\mathrm{N}$ & $\mathrm{N}$ & $\mathrm{N}$ & $\mathbf{N}$ & $\mathrm{N}$ \\
\hline
\end{tabular}

To create minor misspecification, nonzero values were chosen for each 0 loading and correlation by drawing random numbers from a uniform distribution with a mean of 0 , and a range from -.025 to .025 . These values were so close to 0 at their maximum absolute value that they could be regarded as trivial or essentially 0 .

The process of replacing parameters assumed to be 0 in the block-diagonal model with random numbers between -.025 and .025 was carried out 10 times for each of the three sets of correct parameters. Thus there were 30 sets of parameters. Each set of parameters was used in Equation 1 to produce a population matrix. The procedures can be conceived of as resulting in three correct population matrices, each of which is trivially misspecified in $\mathbf{1 0}$ different ways. It is important to note that the error in this simulation was specification error, rather than sampling error. Ten different misspecifications were chosen because it is possible that particular values of errant loadings or correlations are unusually harmful or benign in their effects during parameter estimation.

An example used to generate a population matrix is shown in Table 10, where the entries are rounded to two decimal places (although they were not rounded in the simulation). For each of the 30 matrices, the block-diagonal model was fit to the data.

Results. Table 11 shows the results for each of the solutions. Of the 30 solutions, only 10 converged, and only 6 were admissible. With one exception, $\chi^{2} / d f$ was 0 or negative.

Seven more analyses were subsequently run to further understand the limits of this finding. Trivial misspecifications were discovered in either $\boldsymbol{\Lambda}$ or $\boldsymbol{\Phi}$ that could have caused estimation problems. In one case, a single loading of .022 in $\Phi$ that was incorrectly assumed to be 0 was sufficient to prevent program convergence.

Parameter estimates were quite inaccurate in the runs that converged but showed inadmissible solutions, both in the sign and the magnitude of the estimates. For example, for the population values in $\Phi$ that were $.29, .32$, and .33 , the maximum likelihood estimates were -8.32, 14.303, and .401 , respectively. It would be unwarranted to infer that the first correlation was some negative value close to -1 . Rerunning the program with 
Table 9

Number of Errant Loadings for Each Trait, Factor Loadings, Trait Correlations, and Diagnostics and Problems for 20 Serious Misspecification Solutions (Id = Program Warning That One or More Parameters Might Be Unidentified; Co = Program Converged; $\mathrm{Ad}=$ Solution Was Admissible; $-=\chi^{2}$ Was Negative; $\mathrm{Y}=$ Yes, $\mathrm{N}=\mathrm{No}$ ) (Decimals Points Omitted for Factor Loadings and Trait Correlations)

\begin{tabular}{|c|c|c|c|c|c|c|c|c|c|c|c|c|c|c|c|c|c|c|c|}
\hline \multirow{2}{*}{$\begin{array}{l}\text { Solu- } \\
\text { tion }\end{array}$} & \multicolumn{3}{|c|}{$\begin{array}{l}\text { Number } \\
\text { Errant }\end{array}$} & \multicolumn{9}{|c|}{ Factor Loadings } & \multicolumn{3}{|c|}{$\begin{array}{c}\text { Trait } \\
\text { Correlations }\end{array}$} & \multicolumn{4}{|c|}{$\begin{array}{l}\text { Diagnostics } \\
\text { and Problems }\end{array}$} \\
\hline & $\mathbf{T}_{1}$ & $T_{2}$ & $T_{3}$ & A & B & $\mathrm{C}$ & D & $\mathrm{E}$ & $\mathbf{F}$ & G & $\mathbf{H}$ & I & $S$ & $\mathbf{T}$ & $\mathrm{U}$ & Id & Co & Ad & $\chi^{2} / d f$ \\
\hline 1 & 0 & 0 & 0 & 70 & 75 & 65 & 72 & 76 & 68 & 74 & 67 & 71 & 00 & 00 & 00 & $\mathbf{Y}$ & $\mathbf{Y}$ & $Y$ & 0 \\
\hline 2 & 0 & 0 & 0 & 65 & 60 & 65 & 52 & 56 & 51 & 74 & 67 & 71 & 62 & 67 & 68 & $\mathbf{N}$ & $\mathbf{Y}$ & $\mathbf{N}$ & 0 \\
\hline 3 & 0 & 0 & 0 & 70 & 75 & 65 & 72 & 76 & 68 & 74 & 67 & 71 & 20 & 30 & 40 & $\mathbf{N}$ & $\mathbf{Y}$ & $\mathbf{N}$ & 0 \\
\hline 4 & 0 & 0 & 0 & 70 & 75 & 75 & 71 & 76 & 66 & 69 & 74 & 64 & 70 & 30 & 10 & $\mathbf{Y}$ & $\mathbf{Y}$ & $\mathbf{N}$ & 0 \\
\hline 5 & 0 & 0 & 0 & 55 & 50 & 55 & 42 & 46 & 46 & 74 & 67 & 71 & 82 & 87 & 88 & $\mathbf{N}$ & $\mathbf{Y}$ & $\mathbf{N}$ & 0 \\
\hline 6 & 0 & 0 & 0 & 65 & 60 & 65 & 52 & 56 & 51 & 74 & 67 & 71 & 82 & 87 & 88 & $\mathbf{Y}$ & $Y$ & $\mathbf{N}$ & 0 \\
\hline 7 & 1 & 0 & 0 & 65 & 60 & 55 & 52 & 56 & 51 & 64 & 67 & 61 & 00 & 00 & 00 & $\mathbf{N}$ & $\mathbf{Y}$ & $\mathbf{N}$ & 0 \\
\hline 8 & 2 & 2 & 2 & 65 & 60 & 55 & 52 & 56 & 51 & 64 & 67 & 61 & 00 & 00 & 00 & $\mathbf{N}$ & $\mathbf{Y}$ & $\mathbf{N}$ & 1 \\
\hline 9 & 5 & 3 & 0 & 65 & 60 & 35 & 52 & 56 & 51 & 64 & 67 & 61 & 00 & 00 & 00 & $\mathbf{Y}$ & $\mathbf{N}$ & $\mathbf{N}$ & - \\
\hline 10 & 1 & 0 & 0 & 70 & 60 & 35 & 52 & 56 & 51 & 64 & 67 & 61 & 00 & 00 & 00 & $\mathbf{Y}$ & $\mathbf{N}$ & $\mathbf{N}$ & - \\
\hline 11 & 3 & 0 & 0 & 70 & 75 & 65 & 72 & 76 & 68 & 74 & 67 & 71 & 00 & 00 & 00 & $\mathbf{Y}$ & $Y$ & $\mathbf{N}$ & 0 \\
\hline 12 & 2 & 2 & 2 & 65 & 60 & 55 & 52 & 46 & 51 & 64 & 67 & 61 & 00 & 00 & 00 & $\mathbf{Y}$ & $Y$ & $\mathbf{N}$ & 0 \\
\hline 13 & 3 & 3 & 0 & 70 & 75 & 65 & 72 & 76 & 68 & 74 & 67 & 71 & 00 & 00 & 00 & $\mathbf{Y}$ & $\mathbf{N}$ & $\mathbf{N}$ & 0 \\
\hline 14 & 3 & 3 & 0 & 70 & 75 & 65 & 72 & 76 & 68 & 74 & 67 & 71 & 30 & 00 & 00 & $\mathbf{N}$ & $\mathbf{N}$ & $\mathbf{N}$ & 0 \\
\hline 15 & 3 & 0 & 0 & 70 & 75 & 75 & 72 & 76 & 68 & 74 & 67 & 71 & 30 & 00 & 00 & $\mathbf{N}$ & $\mathrm{Y}$ & $\mathbf{N}$ & 0 \\
\hline 16 & 3 & 3 & 0 & 70 & 75 & 65 & 72 & 76 & 68 & 74 & 67 & 71 & 30 & 45 & 55 & $Y$ & $\mathbf{N}$ & $\mathbf{N}$ & 0 \\
\hline 17 & 2 & 2 & 2 & 65 & 60 & 55 & 52 & 46 & 51 & 64 & 67 & 61 & 10 & 12 & 15 & $\mathrm{~N}$ & $Y$ & $\mathbf{N}$ & 1 \\
\hline 18 & 2 & 2 & 2 & 65 & 60 & 55 & 52 & 46 & 51 & 64 & 67 & 61 & 20 & 22 & 25 & $\mathbf{N}$ & $\mathbf{N}$ & $\mathbf{N}$ & 1 \\
\hline 19 & 2 & 2 & 1 & 55 & 50 & 35 & 42 & 46 & 41 & 54 & 57 & 51 & 30 & 32 & 41 & $Y$ & $\mathbf{N}$ & $\mathbf{N}$ & - \\
\hline 20 & 6 & 4 & 6 & 65 & 60 & 55 & 52 & 46 & 51 & 64 & 67 & 61 & 10 & 12 & 15 & $\mathbf{Y}$ & $\mathbf{N}$ & $\mathbf{N}$ & - \\
\hline
\end{tabular}

some fixed negative value (present convention would be -1 ) would never result in estimates close to the population value.

\section{Discussion}

Recent discussions of MTMM methodology have strongly advocated the use of CFA (Schmitt \& Stults, 1986; Widaman, 1985). The present results question the general utility of a particular CFA approach-the block-diagonal model. The block-diagonal model usually suffers estimation problems when applied to data of substantive interest to psychologists, because of problems such as sampling error, underidentified models, and specification error. The relative frequency of estimation problems in Table 2, even among matrices with relatively large sample sizes, suggests that sampling error is an unlikely explanation of such problems.
Matrices with three methods and three traits were found likely to be identified in practice. The results indicate that block-diagonal models with two methods and four or five traits were frequently unidentified. This finding is important because applications of the block-diagonal model with two methods appear in the literature (e.g., Cote \& Buckley, 1987; Farh et al., 1984; Williams et al., 1989).

Not a single published two-method blockdiagonal analysis yielded an admissible solution. Therefore, it is recommended that the blockdiagonal model should usually be avoided with two-method or two-trait matrices. Alternative CFA approaches that appear to help avoid estimation problems in two-method matrices have been given by Kenny $(1976,1979)$, Marsh (1989), and Marsh and Hocevar (1983).

Another possible explanation for the results 
Table 10

Minor Misspecification of a Block-Diagonal Model With Three Traits and Three Methods

\begin{tabular}{|c|c|c|c|c|c|c|}
\hline \multirow{2}{*}{$\begin{array}{l}\text { Observed } \\
\text { Variable }\end{array}$} & \multicolumn{3}{|c|}{ Trait Factors } & \multicolumn{3}{|c|}{ Method Factors } \\
\hline & $T_{1}$ & $\mathbf{T}_{2}$ & $\mathrm{~T}_{3}$ & $\mathbf{M}_{1}$ & $\mathrm{M}_{2}$ & $\mathbf{M}_{3}$ \\
\hline \multicolumn{7}{|c|}{$\begin{array}{l}\boldsymbol{\Lambda} \text { (Factor Loadings) } \\
\text {. }\end{array}$} \\
\hline $\mathrm{X}_{1}$ & .72 & -.01 & 0.0 & .25 & .02 & .02 \\
\hline $\mathrm{X}_{2}$ & -.01 & .61 & -.00 & .25 & -.02 & .01 \\
\hline $\mathrm{X}_{3}$ & .02 & .02 & .73 & .35 & .01 & -.02 \\
\hline$X_{4}$ & .61 & 0.0 & -.00 & -.02 & .32 & .02 \\
\hline $\mathbf{X}$ & .02 & .71 & -.02 & -.02 & .31 & 0.0 \\
\hline$X_{6}$ & -.02 & -.00 & .62 & .01 & .41 & -.02 \\
\hline $\mathbf{X}_{7}$ & .65 & .01 & -.01 & -.02 & -.02 & .42 \\
\hline $\mathrm{X}_{8}$ & 0.0 & .64 & -.02 & 0.0 & -.01 & .31 \\
\hline $\mathrm{X}_{9}$ & -.02 & .01 & .63 & -.01 & 0.0 & .32 \\
\hline \multicolumn{7}{|c|}{ ( (Factor Correlations) } \\
\hline$T_{1}$ & 1.0 & & & & & \\
\hline $\mathrm{T}_{2}$ & .29 & 1.0 & & & & \\
\hline$T_{3}$ & .30 & .31 & 1.0 & & & \\
\hline $\mathrm{M}_{1}$ & .01 & -.02 & -.02 & 1.0 & & \\
\hline $\mathrm{M}_{2}$ & -.01 & .02 & .01 & .29 & 1.0 & \\
\hline $\mathrm{M}_{3}$ & .01 & .01 & -.02 & .32 & .33 & 1.0 \\
\hline
\end{tabular}

in Table 2 is specification error. The simulation results showed that both serious and trivial misspecification resulted in computational problems, but not necessarily in poor fit by conventional standards. It is quite unlikely that the commonly made assumption that certain parameters equal 0 is precisely correct. Instead, parameters are assumed to be near 0 because minor inaccuracies likely will have little effect on parameter estimates (see also Hattie \& Fraser, 1988). Unfortunately, the effects of minor misspecification are severe in the case of the block-diagonal model, and frequently preclude the interpretation of parameter estimates.

These conclusions are based on simulated data rather than mathematical proof; thus they apply only to the situations simulated here. It could be, for example, that the block-diagonal model applied to MTMM matrices of higher order would show fewer estimation problems, or that the parameters chosen were particularly problematic.

The estimation problems discussed here perhaps can explain the discrepant conclusions concerning method variance in some common measures of organizational variables. Spector
(1987) examined 10 MTMM matrices containing correlations among employee self-report variables, and concluded that there was little method variance in them. Williams et al. (1989) reanalyzed the same data with CFA and reached the opposite conclusion. The latter study fit the block-diagonal model to the matrices and estimated that about $25 \%$ of the variance was attributable to method. All of the seven EQS printouts they provided the present authors ran with constrained parameters-that is, the program fixed values at their theoretical limits during the run. Several of their analyses were replicated using LISREL, and lack of convergence, Heywood cases, negative $\chi^{2}$ values, and various warning messages were found. These estimation problems could have resulted from underidentified parameters and specification error. Also, Marsh (1989) showed that method factors estimated in the block-diagonal model may reflect trait variance rather than method variance. He recommended that CFA estimates of

Table 11

Results and Problems ( $\mathrm{Y}=$ Yes, $\mathrm{N}=\mathrm{No}$ ) for Minor Misspecification Solutions Based on Three Sets of Correct Parameters (Ident Warn = Program Printed a Warning that One or More Parameters Might Be Unidentified;

$-=$ Negative $\chi^{2}$; Parm Equal $=$ Program Recovered the Proper Parameters) (Decimal Points Omitted)

\begin{tabular}{|c|c|c|c|c|c|c|c|c|c|c|}
\hline \multirow{2}{*}{$\begin{array}{l}\text { Set and } \\
\text { Result }\end{array}$} & \multicolumn{10}{|c|}{ Solution } \\
\hline & 1 & 2 & 3 & 4 & 5 & 6 & 7 & 8 & 9 & 10 \\
\hline \multicolumn{11}{|l|}{ Set 1} \\
\hline Iden & $\mathrm{Y}$ & $\mathrm{Y}$ & Y & $\mathbf{N}$ & $\mathbf{N}$ & $\mathrm{N}$ & $\mathbf{N}$ & $\mathbf{N}$ & $\mathbf{N}$ & $\Lambda$ \\
\hline Cor & $\mathbf{N}$ & $\mathbf{N}$ & $\mathrm{N}$ & $\mathbf{N}$ & $\mathbf{Y}$ & $\mathrm{N}$ & & $\mathbf{N}$ & $\mathbf{N}$ & \\
\hline & $\mathrm{N}$ & $\mathbf{N}$ & $\mathrm{N}$ & $\mathbf{N}$ & $Y$ & $\mathbf{N}$ & v & $\mathbf{N}$ & $\mathrm{N}$ & $\mathrm{N}$ \\
\hline$\chi^{2 / d f}$ & - & - & - & 0 & 0 & & & - & - & \\
\hline \multicolumn{11}{|l|}{ Set 2} \\
\hline Ident Warn & $\mathbf{Y}$ & $\mathrm{Y}$ & $\mathrm{N}$ & $\mathrm{Y}$ & $\mathbf{N}$ & $\mathbf{N}$ & $\mathbf{N}$ & $\mathrm{Y}$ & $\mathbf{N}$ & $\mathbf{N}$ \\
\hline & $\mathrm{N}$ & $\mathbf{N}$ & $Y$ & $\mathrm{~N}$ & $Y$ & $Y$ & $Y$ & $\mathrm{~N}$ & $\mathbf{N}$ & $\mathbf{Y}$ \\
\hline & $\mathbf{N}$ & $\mathbf{N}$ & $\mathrm{Y}$ & $\mathbf{N}$ & $\mathbf{N}$ & $\mathbf{N}$ & $\mathbf{N}$ & $\mathbf{N}$ & $\mathbf{N}$ & $\mathbf{N}$ \\
\hline$\chi^{2} / d f$ & - & - & 0 & - & 0 & 0 & 0 & - & 0 & \\
\hline \multicolumn{11}{|l|}{ Set 3} \\
\hline Ident & $\mathrm{N}$ & $\mathbf{N}$ & $\mathrm{N}$ & $\mathbf{N}$ & $\mathbf{N}$ & $\mathbf{N}$ & $\mathrm{N}$ & $\mathrm{N}$ & $\mathbf{N}$ & $\mathbf{N}$ \\
\hline & $\mathrm{N}$ & $Y$ & $\mathrm{~N}$ & $Y$ & $N$ & $\mathrm{~N}$ & $Y$ & $\mathrm{~N}$ & $\mathrm{~N}$ & $Y$ \\
\hline & $\mathrm{N}$ & $\mathrm{Y}$ & $\mathrm{N}$ & $\mathrm{Y}$ & $\mathrm{N}$ & $\mathbf{N}$ & 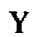 & $\mathrm{N}$ & $\mathbf{N}$ & $\mathbf{Y}$ \\
\hline$\chi^{2} / d f$ & 0 & 0 & 0 & 0 & - & - & 0 & 0 & 0 & 0 \\
\hline
\end{tabular}


method variance be viewed with suspicion if such estimates are at odds with inferences drawn from inspection of the MTMM matrix.

The full value of confirmatory techniques can be achieved only when a well-developed and plausible model has been developed from which to start. If this were to include a theory that specified how traits and methods interrelate, the blockdiagonal model could be useful in testing the feasibility of that theory, assuming that the model was identified. Letting the data determine which parameters to estimate, however, is quite hazardous and is unlikely to be helpful (Kaplan, 1988; MacCallum, 1986).

Of particular concern in the CFA analyses of MTMM matrices is the specification of method factors. Method effects have typically been regarded as any sort of nuisance variable that confounds results of interest. The specification and interpretation of method factors in CFA, however, requires some sort of rationale for the particular pattern of parameters to be estimated - whether it be fatigue effects in physical ability measurements, defensiveness in personality assessment, or reactivity to measurement. For example, suppose that three different self-report formats were used to investigate each of three interests: nature, sports and sexual practices. It is likely that a defensive or self-serving bias could enter into all three reports of sexual practices (but not interest in nature or sports). Method variance defined as distortion or defensive bias would properly load across methods (i.e., formats) in this example, but only for measures of sexual practices.

Researchers should not rely on the blockdiagonal model or any other CFA model as the general representation of MTMM data. A specific model should be developed that is hypothesized to account for the particular problem at hand (Widaman, 1985, p. 7). Although it is relatively easy to hypothesize trait factors based on their substantive meaning, it is much more difficult to assign substantive meaning to method factors.

The results presented above suggest that researchers who use the block-diagonal model should carefully assess the identification of their models, and should be wary of computational problems and parameter estimates that fall beyond theoretical limits. Researchers should avoid interpreting estimates when estimation problems occur. The finding that trivial misspecification typically results in poor parameter estimates suggests that the block-diagonal method of analyzing the MTMM matrix is less useful than has generally been thought.

\section{References}

Arora, R. (1982). Validation of an S-O-R model for situation, enduring, and response components of involvement. Journal of Marketing Research, 19, 505-516.

Bentler, P. M. (1985). Theory and implementation of $E Q S$, a structural equations program. Los Angeles CA: BMDP Statistical Software, Inc.

Campbell, D. T., \& Fiske, D. W. (1959). Convergent and discriminant validation by the multitraitmultimethod matrix. Psychological Bulletin, 56, 81-105.

Campbell, D. T., \& O'Connell, E. J. (1967). Method factors in multitrait-multimethod matrices: Multiplicative rather than additive? Multivariate Behavioral Research, 4, 389-418.

Coovert, M. D., Penner, L. A., \& MacCallum, R. (1990). Covariance structure modeling in personality and social psychological research: An introduction. In C. Hendrick \& M. Clark (Eds.). Research methods in personality and social psychology. Newbury Park CA: Sage.

Cote, J. A., \& Buckley, R. B. (1987). Estimating trait, method, and error variance: Generalizing across 70 construct validation studies. Journal of Marketing Research, 24, 315-318.

Dickinson, T. L., \& Tice, T. E. (1973). A multitraitmultimethod analysis of scales developed by retranslation. Organizational Behavior and Human Performance, 9, 421-438.

Dillon, W. R., Kumar, A., \& Mulani, N. (1987). Offending estimates in covariance structure analysis: Comments on the causes of and solutions to Heywood cases. Psychological Bulletin, 101, 126-135.

Dunham, R., Smith, F., \& Blackburn, R. (1977). Validation of the index of organizational reactions with the JDI, MSQ, and the Faces scales. Academy of Management Journal, 20, 420-432.

Farh, J., Hoffman, R. C., \& Hegarty, W. H. (1984). Assessing environmental scanning at the subunit level: A multitrait-multimethod analysis. Decision Science, 15, 197-219. 
Flamer, S. (1983). Assessment of the multitraitmultimethod matrix validity of Likert scales via confirmatory factor analysis. Multivariate Behavioral Research, 18, 275-308.

Golding, S. L., \& Seidman E. (1974). Analysis of multitrait-multimethod matrices: A two step principal components procedure. Multivariate Behavioral Research, 9, 479-496.

Hattie, J., \& Fraser, C. (1988). The constraining of parameters in restricted factor analysis. Applied Psychological Measurement, 12, 155-162.

Jackson, D. N. (1971). Comments on "Evaluation of multimethod factor analysis." Psychological Bulletin, 75, 421-423.

Jackson, D. N. (1975). Multimethod factor analysis: A reformulation. Multivariate Behavioral Research, 10, 259-275.

James, L. R., Mulaik, S. A., \& Brett, J. M. (1982). Causal analysis: Assumptions, models, and data. Beverly Hills CA: Sage.

Jöreskog, K. G., \& Sörbom, D. (1984). LISREL VI: Analysis of linear structural relationships by maximum likelihood, instrumental variables, and least squares methods (3rd ed.). Mooresville IN: Scientific Software, Inc.

Kaplan, D. (1988). The impact of specification error on the estimation, testing, and improvement of structural equation models. Multivariate Behavioral Research, 23, 69-86.

Karst, T. O., \& Most, R. (1973). A comparison of stress measures in an experimental analogue to public speaking. Journal of Consulting and Clinical Psychology, 4, 342-48.

Kelly. E. L., \& Fiske, D. W. (1951). The prediction of performance in clinical psychology. Ann Arbor MI: University of Michigan Press.

Kenny, D. A. (1976). An empirical application of confirmatory factor analysis to the multitraitmultimethod matrix. Journal of Experimental Social Psychology, 12, 247-252.

Kenny, D. A. (1979). Correlation and causality. New York: Wiley.

Kothandapani, V. (1971). Validation of feeling, belief, and intention to act as three components of attitude and their contribution to prediction of contraceptive behavior. Journal of Personality and Social Psychology, 19, 321-333.

Lawler, E. E. III (1967). The multitrait-multimethod approach to measuring managerial job performance. Journal of Applied Psychology, 51, 369-381.
Long, J. S. (1983). Confirmatory factor analysis. Beverly Hills CA: Sage.

MacCallum, R. (1986). Specification searches in covariance structure modeling. Psychological Bulletin, 100, 107-120.

Marsh, H. W. (1989). Confirmatory factor analyses of multitrait-multimethod data: Many problems and a few solutions. Applied Psychological Measurement, 13, 335-361.

Marsh, H. W., \& Hocevar, D. (1983). Confirmatory factor analysis of multitrait-multimethod matrices. Journal of Educational Measurement, 20, 231-248.

Marsh, H. W., \& Hocevar, D. (1988). A new, more powerful approach to multitrait-multimethod analyses: Application of second-order confirmatory factor analysis. Journal of Applied Psychology, 73, 107-117.

Meier, S. (1984). The construct validity of burnout. Journal of Occupational Psychology, 57, 211-219.

Ostrom, T. M. (1969). The relationship between affective, behavioral, and cognitive components of attitude. Joumal of Experimental Social Psychology, 5, 12-30.

SAS Institute. (1982). SAS User's Guide: Statistics, 1982 edition. Cary NC: Author.

Schmitt, N., \& Stults, D. M. (1986). Methodology review: Analysis of multitrait-multimethod matrices. Applied Psychological Measurement, 10, 1-22.

Shepherd, G. (1977). A critique and extension of Bronfenbrenner's moral dilemma test. International Journal of Psychology, 12, 207-217.

Spector, P. E. (1987). Method variance as an artifact in self-reported affect and perceptions at work: Myth or significant problem? Journal of Applied Psychology, 72, 438-443.

Widaman, K. F. (1985). Hierarchically nested covariance structure models for multitrait-multimethod data. Applied Psychological Measurement, 9, 1-26.

Williams, L. J., Cote, J. A., \& Buckley, M. R. (1989). The lack of method variance in self-reported affect and perceptions at work: Reality or artifact? Journal of Applied Psychology, 74, 462-468.

Wothke, W. (1984). The estimation of trait and method components in multitrait-multimethod measurement. Unpublished doctoral dissertation, University of Chicago, Chicago.

Wothke, W. (1987, April). Multivariate linear models of the multitrait-multimethod matrix. Paper presented at the meeting of the American Educational Research Association, Washington DC, U.S.A. 


\section{Acknowledgments}

The authors thank Dennis Hocevar for sharing a portion of the data used in Marsh and Hocevar (1988) and reported in Table 2, and Herbert W. Marsh for providing a MTMM matrix (Marsh \& Hocevar, 1983) that ran without estimation problems. Thanks are also due to Werner Wothke and Gordon Waugh for comments on an earlier draft of this manuscript, and Joseph A. Cote for providing printouts of analyses used in Williams et al. (1989).
Finally, thanks are due to two anonymous reviewers, whose comments were very helpful, especially for the suggestion to simulate minor misspecification.

\section{Author's Address}

Send requests for reprints or further information to Michael T. Brannick, Psychology Department, University of South Florida, Tampa, FL 33620, U.S.A. 